\title{
History of infection control and its contributions to the development and success of brain tumor operations
}

\author{
Jason T. Miller, B.S., Scott Y. Rahimi, M.D., and Mark Lee, M.D., Ph.D. \\ Department of Neurosurgery, Medical College of Georgia, Augusta, Georgia
}

\begin{abstract}
Before advancements in infection control, only conditions that brought patients near death warranted the risk of surgical intervention. If patients survived the operation, infection was nearly inevitable and death by overwhelming sepsis was knocking at their door. In the late 19th century, with the development of germ theory by Louis Pasteur and its subsequent application to surgical sterility by Joseph Lister, surgeons were able to operate with a substantially reduced risk of infection. Consequently, surgeons became more confident and began to explore more extravagant procedures, including elective operations within the cranial vault. As scientific knowledge expanded in the 20th century, so did the advancement of infection control with the use of prophylactic antibiotic drugs, heat sterilization of instruments, and microbial barriers. Recent reports have placed the rate of complications due to infection between 0.75 and $2.32 \%$ for intracranial operations.
\end{abstract}

KEY WORDS • infection • brain tumor • history of neurosurgery

\begin{abstract}
"Certainly infections cannot be attributed to the intervention of the devil but must be laid at the surgeon's door" Harvey Cushing $^{5}$

The late 19th century brought about advances in anesthesia, hemostasis, localization techniques, and infection control that reduced the risks associated with surgical treatment of intracranial masses to acceptable levels. Even after the development of tumor localization, surgeons approached the sanctuary of the mind with trepidation for fear of deadly complications. Infection was the major contributor to morbidity and mortality rates, occurring after practically all operations and taking the lives of almost half of all surgical patients. ${ }^{1}$ Consequently, surgical procedures were attempted only as a last resort. The application of germ theory to wound healing changed the practice of surgery and set the stage for the development of brain tumor surgery.
\end{abstract}

\section{Early Wound Management}

The earliest known attempts to access the calvaria date to circa 10,000 BC. Skulls collected throughout the world show the square and ovoid marks left by the ancient "healers" who ground and scraped the skull with sharpened stones. Some patients survived, as evidenced by the smoothed corners of some Neolithic skulls found in East Africa. ${ }^{4,17}$ Nevertheless, it may be assumed that the mortality and morbidity rates were less than acceptable by today's standards.
Some years after the Neolithic era, surgeons may have taken a more conservative approach to opening skulls. Under the guidelines imposed by The Code of Hammurabi (circa $1750 \mathrm{BC}$ ), surgeons in Mesopotamia were provided monetary compensation for their services; however, if the patient died under their care, the surgeon's hands were amputated. ${ }^{7}$ With these stakes, many surgeons may have limited their caseload of elective surgical procedures. Around this time the first account of attempted wound management appeared. The world's oldest medical text outlines the procedures for wound management practiced by the Sumerians. The wound was cleansed with beer and then bandaged with a cloth soaked in wine and turpentine. ${ }^{4}$ The practice of using alcoholic beverages and turpentine would remain the treatment of choice until the modern era. ${ }^{1}$

\section{Pre-Listerian Philosophies}

The proliferation of medical texts originating from the Golden Age of Greece would provide guidelines for the practice of medicine for 2000 years. Nevertheless, because of the intellectual rigidity of the medical community, expansion on the ideas and practices of the Greeks would remain stagnant for the same two millennia. ${ }^{7}$ Every few hundred years, courageous men dedicated to the practice of the healing arts would challenge the false assertions and even produce verifiable data to support their claims, but their ideas would not wield the influence necessary to cause 
change. In the practice of wound healing, two issues would become recurring points of contention: first, the role of suppuration; and second, the origin and transmissibility of infection.

\section{Laudable Pus}

Hippocrates (circa 460-370 BC) may have been the first to hold an opinion on suppuration, asserting that the formation of pus was not a natural component in the healing process and suppuration should be avoided. His recommendations for managing wounds were similar to those of the Sumerians: cleansing with wine, applying a bandage, and then pouring wine on the bandage. ${ }^{4}$

Claudius Galen (circa A.D. 130-200), a surgeon to the gladiators in Pergamum, idealized Hippocrates and championed Hippocratic doctrines in the practice of medicine. Galen was a prolific writer on the science of medicine and became an outspoken proponent for experimentation, encouraging the questioning of established doctrines to expand scientific knowledge. (Ironically, his ideas became an established orthodoxy and prevailed unquestioned for 15 centuries.) His works were translated into many languages and became the lexicon for medical practice until the modern era. Many of his assertions proved true; however, one very important assumption was horrifically incorrect: that the formation of pus was essential for wound healing. This deviation from the Hippocratic dogma is one that would plague surgeons and hinder surgical progress until the time of Lister. ${ }^{1}$

One thousand years later, Theodoric Borgognoni of Cervia (1205-1298) challenged Galen's view of suppuration. Theodoric dedicated much of his career to finding the ideal conditions for wound healing and settled on four essentials: control of bleeding, removal of contaminated or necrotic material, avoidance of dead space, and careful application of the wound dressing. He also strongly emphasized the avoidance of "laudable" pus. ${ }^{16}$ Nevertheless, because his views were in opposition to the established orthodoxy of Galen, he was denounced by his colleagues and the church. ${ }^{4}$ Galen's doctrine of suppuration would remain the rule for wound management until the late 19th century.

That surgeons welcomed the sight of a purulent wound may be explained by the environment in which they were forced to practice. Wounds could be classified into two different categories: those with suppuration and those without. Wounds productive of a creamy, yellow ooze tended to run a chronic course, taking months to heal, but the patients were generally free of systemic symptoms. ${ }^{15}$ As Alexander ${ }^{1}$ recounts, it was noted by Steven Smith as late as 1887 that "amputation wounds rarely, if ever, recovered at Bellevue, except after long-continued suppuration." Conversely, a thin, watery discharge was associated with a fatal outcome, with the patient dying of sepsis within days. With an infection rate of almost $100 \%$, a purulent wound represented the lesser of the two evils. Therefore, it is of little wonder that even the most conscientious surgeons preferred and even encouraged the formation of pus.

\section{Transmissibility of Infectious Agents}

Another issue that proved elusive to science before the 19th century was the origin and transmissibility of infection. As recounted in Alexander, ${ }^{1}$ more than a century be- fore Leeuwenhoek's microscope and three centuries before Pasteur's studies on putrefaction, Hieronymus Fracastorius (1478-1553) postulated that the cause of infectious disease was from invisible living seeds (seminaria contagionum). In his work, "De contagione," published in 1546, he described three modes of disease spread: direct contact with infected persons, indirect contact with fomites, and airborne transmission (see Meade ${ }^{11}$ ). As Hamby ${ }^{8}$ reported, Ambroïse Paré (1510-1590), considered the father of modern surgery, similarly believed infection was introduced from the environment. Furthermore, others after Fracastorius and Paré correctly noted the importance of a sterile environment in the prevention of disease transmission. In 1822 Gaspard demonstrated the pathogenicity of suppuration by injecting pus into a dog, and when that dog fell ill, injecting its blood into another animal, causing death. ${ }^{1}$ According to two histories of surgery, ${ }^{11,17}$ in 1842 Oliver Wendell Holmes of Harvard recommended that physicians wash their hands with a calcium chloride solution to prevent the spread of infection from the autopsy rooms to the wards. Similarly, Ignaz Philipp Semmelweis (1818-1865), in his attempt to universalize the practice of hand washing, reported that hand washing with chloride of lime solution reduced puerperal sepsis mortality from 9.92 to $1.27 \%$ in 2 years. ${ }^{1,11}$ The views of both Holmes and Semmelweis encountered a cold reception from the medical community.

As a result, operations were performed with little regard for a sterile environment. Surgeons' hands, rarely washed, were placed directly into the patient's wounds. Frequently, onlookers were encouraged to "take a feel" for educational purposes. ${ }^{1}$ Surgical instruments were crudely wiped, placed back into their velvet carriers, and reused, some having been sharpened on the sole of the surgeon's boot. ${ }^{15}$ The floors of the surgical wards were covered with human feces, urine, blood, and pus, and the hospital walls displayed a collage of phlegm. Consequently, infection was a major cause of death, with $80 \%$ of operations plagued by "hospital gangrene" and a nearly $50 \%$ mortality rate. ${ }^{1}$ The stench of dead bodies and infectious byproducts led some to believe that putrid wounds were caused by particles in the air or bad "humors." In 1880, William Halsted reportedly operated in tents outside of Bellevue Hospital for better ventilation. ${ }^{17}$ The prevailing view was that if infectious particles did exist, then they arose by spontaneous generation.

\section{Infectious Disease and Antisepsis}

Louis Pasteur (1822-1895) vanquished the long-held myth of spontaneous generation and attributed fermentation and meat putrefaction to living microscopic organisms. It was the simplicity and rationality of his experiments that persuaded many of his contemporaries to adopt germ theory. 7,11

Joseph Lister (1827-1912; Fig. 1), a professor of surgery at Glasgow, was the first to see the connection between Pasteur's discovery of the fermentation process and the suppuration of wounds. In April 1867 he published his ground-breaking paper on antisepsis, stating that "all the local inflammatory mischief and general febrile disturbance which follow severe injuries are due to the irritating and poisoning influence of decomposing blood or sloughs." Lister began applying carbolic acid to compound fracture 
wounds. The wound healed without suppuration, amputation was averted, and the mortality rate from amputation plummeted from 45 to $15 \%$.

In 1876, Lister traveled to the US to present his ideas at the International Medical Congress in Philadelphia. In attendance was William W. Keen (1837-1932; Fig. 2) of Jefferson Medical College in Philadelphia, who had garnered a formidable reputation in cranial surgery. Keen was one of the few surgeons who realized the practical importance of infection control, and he became one of the first American surgeons to implement Lister's system. ${ }^{7}$ The following is a description of Keen's surgical setup:

All carpets and unnecessary furniture were removed from the patient's room. The walls and ceiling were carefully cleaned the day before operation, and the woodwork, floors, and remaining furniture were scrubbed with carbolic solution. This solution was also sprayed in the room on the morning preceding but not during the operation. On the day before the operation, the patient's head was shaved, scrubbed with soap and water, and ether, and covered with wet corrosive sublimate dressing until operation, then ether and mercuric chloride washings were repeated. The surgical instruments were boiled in water for 2 hours, and new deep-sea sponges (elephant ears) were treated with carbolic and sublimate solutions before usage. The surgeon's

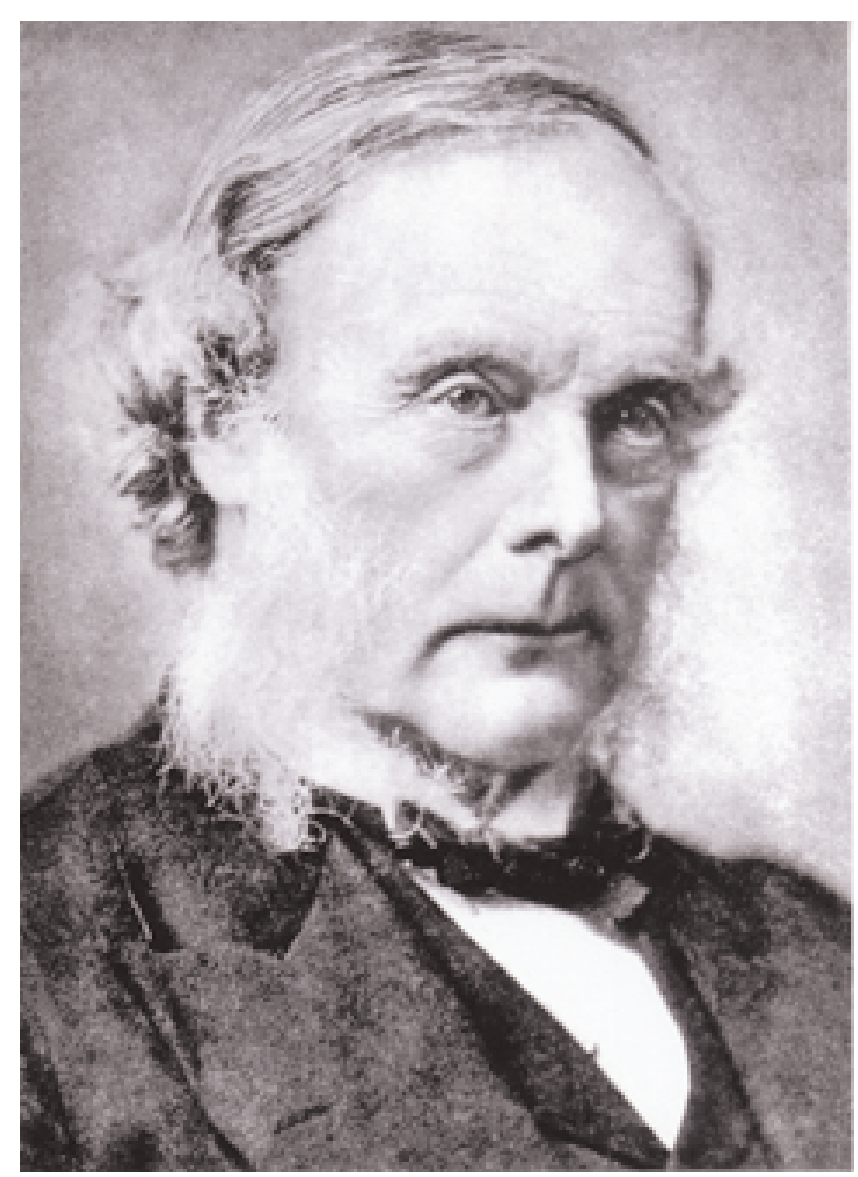

Fig. 1. Photograph of Joseph Lister (1827-1912). (Courtesy of Historical Section of the National Library of Medicine, Bethesda, Maryland.)

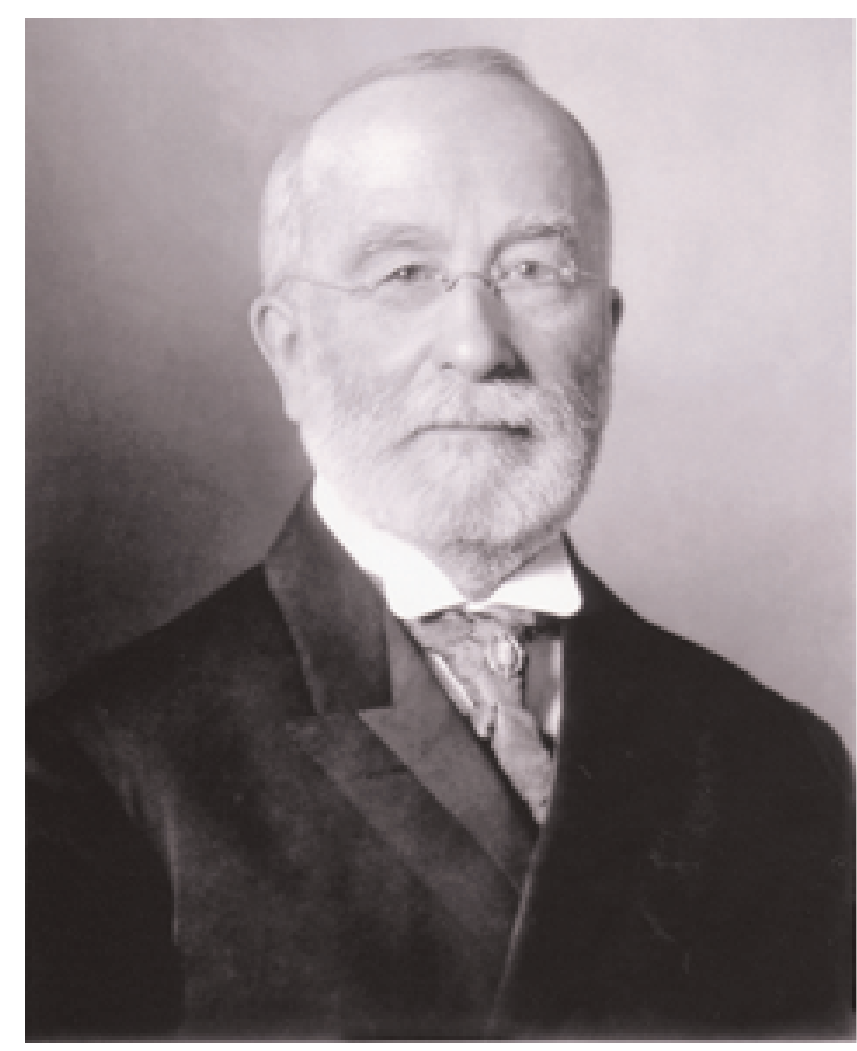

Fig. 2. Photograph of William Williams Keen Jr. (1837-1932), a pioneer American neurological surgeon. (Courtesy of Historical Section of the National Library of Medicine, Bethesda, Maryland.)

hands were cleaned and disinfected by soap and water, alcohol, and sublimate solution. ${ }^{15}$

\section{Advancements in Asepsis}

Improving on listerian practices, in 1891 Ernst von Bergmann introduced heat sterilization of instruments, which proved superior to chemical sterilization. Sterile gowns and caps were introduced in 1883 by Gustav Neuber of Kieland, and then the surgical mask by Mikulicz in $1897 .{ }^{11}$ The use of rubber gloves became widespread after 1890 when William Stewart Halsted (1852-1922; Fig. 3) commissioned the Goodyear rubber company to fashion gloves for his nurse to protect her hands from the mercuric chloride solutions used to disinfect the instruments. ${ }^{13}$

\section{Brain Tumors}

Although principles of cleanliness and sterility were slow to become universally accepted, the surgeons who implemented them found new confidence to explore more complicated procedures. As localization of intracranial lesions became more refined, surgical intervention emerged as a more plausible option. In 1879, while the application of Lister's principles was still in its infancy, Glasgow's Sir William Macewen (1848-1924) removed a meningioma, after which the patient lived for 8 more years, eventually dying of Bright disease. By 1888, Macewen had reported on 21 neurosurgical operations, with three deaths and 18 successful recoveries-results that he attributed to cerebral 


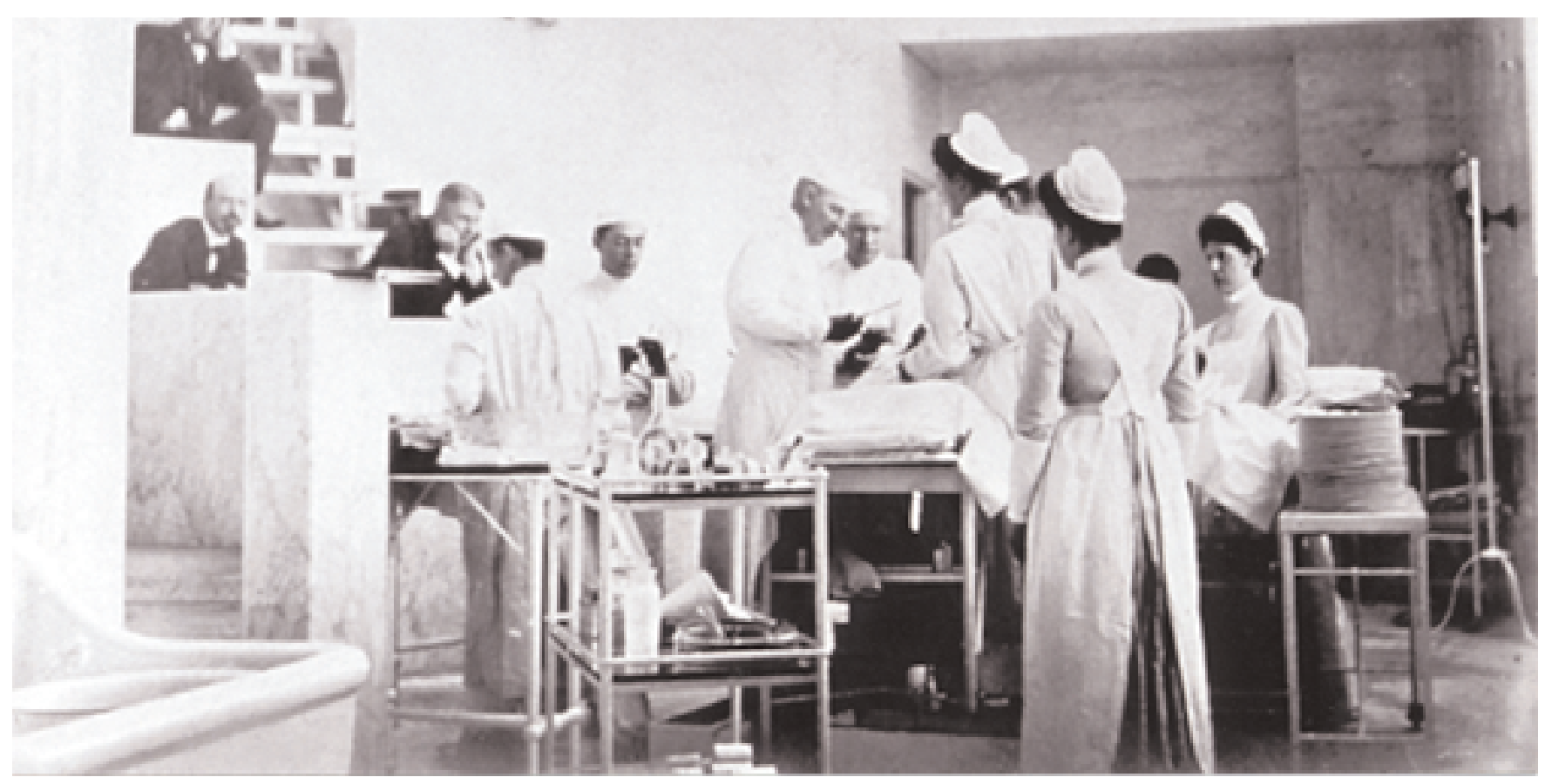

Fig. 3. Photograph of Harvey Cushing and William Halsted in the operating room. (Courtesy of Historical Section of the National Library of Medicine, Bethesda, Maryland.)

localization and good aseptic technique. ${ }^{7}$ In 1884, Sir Rickman Godlee (1849-1925) removed the first parenchymal tumor diagnosed and localized solely by neurological evidence. ${ }^{18}$ The patient survived the procedure with only mild neurological complications, but eventually died of postoperative infection. Four years later, Keen became the first American surgeon to operate electively on the brain, removing a meningioma in a young man who recovered with minimal deficit and went on to live another 30 years. When the man's body was returned to Keen for autopsy, there was no evidence of tumor recurrence. ${ }^{15}$

Harvey Cushing (1869-1939), under the tutelage of William Halsted, became committed to precision and meticulous surgical technique, producing phenomenal results. In 1915, of 130 surgically treated tumor cases, he reported an $8.4 \%$ mortality rate. Of these deaths, only one was due to infection; the patient died of streptococcal meningitis on the 6th day postsurgery. With results far surpassing his contemporaries and rivaling even today's morbidity and mortality numbers, Cushing explained his success this way:

[Our results] depend so greatly on such details as perfection of anaesthesia, scrupulous technique, ample expenditure of time, painstaking closure of wounds without drainage, and a multitude of other elements, which so many operators impatiently regard as triviality. ${ }^{5}$

\section{THE 20TH CENTURY}

In the 1940s, after the refinement and production of Alexander Fleming's Penicillium mold extract, antibiotic prophylaxis served as a more advanced form of antisepsis, further reducing postoperative infection. ${ }^{2}$ Today, a variety of antibiotics are used and are chosen specifically for the organisms anticipated to cause the infection. Recent efforts in infection control have been focused on isolating and eliminating the variables that increase the risk for infection. In 1997, on behalf of her colleagues, Korinek ${ }^{10}$ reported on a multicenter study involving 2944 patients, in which univariate and multivariate analysis was used to determine the incidence of risk factors for surgical site infections after craniotomy. She found essentially two variables in this analysis that increased the risk of infection: leakage of cerebrospinal fluid and a recent history of craniotomy, both of which are dependent on the quality of surgical technique.

Because elective craniotomies were nonexistent before the late 19th century, it is impossible to quantify precisely Lister's impact on neurosurgical infections; however, it may be safe to conclude that little improvement has been made since his techniques were implemented. The Centers for Disease Control data from January 1992 through June 2003 showed that the infection rate among craniotomies (not specific for tumor resection), depending on the risk index category, ranged from $0.86 \%$ (low risk) to $2.32 \%$ (high risk). ${ }^{12}$ Sawaya, et al.,${ }^{14}$ have recently reported data on 400 craniotomies performed specifically for the treatment of cranial tumors. They showed a wound complication rate of $0.75 \%$ and a meningitis rate of $1 \%$. Others report wound complication rates of $1.9 \%{ }^{3}$ and $1.5 \% .{ }^{6}$ Compare these numbers to Cushing's, ${ }^{5}$ who boasted a $1 \%$ infection rate more than 80 years earlier!

\section{CONCLUSIONS}

From ancient times to the 19th century, infection served as a great impediment to surgical progress. Static dogma 


\section{History of infection control and success of brain tumor surgery}

predominated as the means by which surgical decisions were made. Such dogma was based on false assumptions derived from limited empirical evidence. Surgeons and "scientists" did not engage in communication about results, and most practitioners maintained a rigid stance about the beliefs they had adopted, although they could not explain why contrary practices occasionally provided better outcomes. It would take many thousands of years before the system of thought in surgery would be transformed from orthodoxy to our modern dynamic scientific method. Within this philosophical framework, Louis Pasteur shook the mythical underpinnings of wound putrefaction and provided a framework on which Lister built the system of antisepsis. After a few talented and courageous men decided to adopt sterile practices, surgery was transformed and neurosurgery was born.

"Antisepsis relieved patients from the terrors of death and gave to the surgeon restful nights and joyous days." William Williams Keen ${ }^{9}$

\section{References}

1. Alexander JW: The contributions of infection control to a century of surgical progress. Ann Surg 201:423-428, 1985

2. Barker FG II: Efficacy of prophylactic antibiotics for craniotomy: a meta-analysis. Neurosurgery 35:484-492, 1994

3. Cabantog AM, Bernstein M: Complications of first craniotomy for intra-axial brain tumor. Can J Neurol Sci 21:213-218, 1994

4. Cruse PJE: History of surgical infection, in Fry DE (ed): Surgical Infections. Boston: Little, Brown, 1994, pp 3-10

5. Cushing H: Concerning the results of operations for brain tumor. JAMA 64:189-195, 1915

6. Fadul C, Wood J, Thaler H, et al: Morbidity and mortality of craniotomy for excision of supratentorial gliomas. Neurology 38:1374-1379, 1988

7. Goodrich JT: Landmarks in the history of neurosurgery, in Ren- gachery SS, Wilkins RH (eds):Principles of Neurosurgery. Baltimore: Mosby-Wolfe, 1994, pp 1.2-1.25

8. Hamby WB: Ambroise Paré: Surgeon of the Renaissance. St. Louis: Warren H Green, 1967, p 110

9. Keen WW: Before and after Lister. Science 41:845-853, 1915

10. Korinek AM: Risk factors for neurosurgical site infections after craniotomy: a prospective multicenter study of 2944 patients. The French Study Group of Neurosurgical Infections, the SEHP, and the C-CLIN Paris-Nord. Service Epidemiologie Hygiene et Prevention. Neurosurgery 41:1073-1079, 1997

11. Meade RH: An Introduction to the History of General Surgery. Philadelphia: WB Saunders, 1968, pp 29-37

12. National Nosocomial Infections Surveillance (NNIS) System: National Nosocomial Infections Surveillance (NNIS) System Report, data summary from January 1992 through June 2003, issued August 2003. Am J Infect Control 31:481-498, 2003

13. Randers-Pehrson JD: The Surgeon's Glove. Springfield, IL: Charles C Thomas, 1960

14. Sawaya R, Hammoud M, Schoppa D, et al: Neurosurgical outcomes in a modern series of 400 craniotomies for treatment of parenchymal tumors. Neurosurgery 42:1044-1056, 1998

15. Stone JL: W.W. Keen: America's pioneer neurological surgeon. Neurosurgery 17:997-1010, 1985

16. Teodorico: The Surgery of Theodoric, ca. A.D. 1267 (translated by Campbell E, Colton J). New York: Appleton-Century-Crofts, 1955

17. Wangensteen $\mathrm{OH}$, Wangensteen SD, Klinger CF: Surgical cleanliness, hospital salubrity, and surgical statistics, historically considered. Surgery 71:477-493, 1972

18. Wilkins RH: History of neurosurgery, in Wilkins RH, Rengachary SS (eds):Neurosurgery. McGraw-Hill, 1995, Vol 1, pp 25-36

Manuscript received February 15, 2005.

Accepted in final form March 15, 2005.

Address reprint requests to: Scott Rahimi, M.D., Department of Neurosurgery, Medical College of Georgia, 1120 15th Street, Augusta, Georgia 30912. email: srahimi@mail.mcg.edu. 